\title{
KUALITAS PELAYANAN DAN PROMOSI MEMPENGARUHI KEPUTUSAN MAHASISWA KULLIAH DI STIE BENTARA PERSADA BATAM
}

\author{
IMELDA TAMBA,FELIKS DABUR,ESTER \\ Sekolah Tinggi Ilmu Ekonomi Bentara Persada imelday36@gmail.com, \\ felixpondo@gmail.com, turnpester@gmail.com
}

\begin{abstract}
The study of the research that the researchers did was the influence of Service Quality and Promotion on Student Decisions. Lecture at STIE Bentara Persada Batam. With the object of reseach on STIE Bentara Persada Batam students. The purpose of this study was to determine the effect of Service Quality and Promotion on Student Decision Lecture at STIE Bentara Persada Batam. This study used a sample of 70 students at STIE Bentara Persada Batam with the chosen sample technique being saturated sampling. Data collection techniques in this study used a questionnaire. The results showed that, Service Quality and Promotion partially had a positive and significant effect on Student Decision Lecture at STIE Bentara Persada Batam. The regression analysis results obtained a coefficient of determination (R2) of 0.175which means that student decisions areinfluenced by Service Quality and Promotion by $17.5 \%$, while the remaining $82.5 \%$ is influenced by other variables not examined inthis study.
\end{abstract}

Keywords: Service Quality, Promotion and Student decisions.

Abstrak: Kajian dari penelitian yang peneliti lakukan adalah pengaruh Kualitas Pelayanan Dan Promosi Terhadap Keputusan Mahasiswa Kuliah di STIE Bentara Persada Batam. Dengan objek penelitian pada mahasiswa STIE Bentara Persada Batam. Tujuan penelitian ini adalah untuk mengetahui adanya pengaruh antara Kualitas Pelayanan Dan Promosi Terhadap Keputusan Mahasiswa Kuliah di STIE Bentara Persada Batam. Penelitian ini menggunakan sampel sebanyak 70 mahasiswa di STIE Bentara Persada Batam dengan teknik sampel yang dipilih adalah sampling jenuh. Teknik pengumpulan data dalam penelitian ini menggunakan kuesioner. Hasil penelitian menunjukkan bahwa, Kualitas Pelayanan Dan Promosi secara parsial berpengaruh positif dan signifikan terhadap Keputusan Mahasiswa Kuliah di STIE Bentara Persada Batam. Hasil analisis regresi memperoleh nilai koefisien determinasi $\left(\mathrm{R}^{2}\right)$ sebesar 0,175 yang berarti bahwa keputusan mahasiswa dipengaruhi oleh kualitas pelayanan dan promosi sebesar 17,5\%, sedangkan sisanya 82,5\% dipengaruhi oleh variabel lain yang tidak diteliti dalam penelitian ini.

Kata Kunci: Kualitas Pelayanan, Promosi , dan Keputusan Mahasiswa

\section{A. Pendahuluan}

Dunia pendidikan dan belajar merupakan satu aspek yang sangat penting bagi peningkatan kualitas sumber daya manusia. Sumber daya manusia yang berkualitas akan mampu menggerakkan semua aspek kehidupan. Dengan belajar di dunia pendidikan, maka manusia akan menjadi sumber daya yang dapat diandalkan. Di era globalisasi saat ini, pertumbuhan lembaga pendidikan di Indonesia semakin bertambah pesat, hal ini ditandai dengan munculnya Universitas, Sekolah Tinggi maupun Akademi yang ada di Indonesia pada umumnya dan khususnya di kota Batam. Dengan meningkatnya jumlah lembaga pendidikan yang ada, maka persaingan antar Perguruan 
Tinggi khususnya Perguruan Tinggi swasta untuk mendapatkan mahasiswa baru semakin ketat.

Perkembangan teknologi yang berhubungan dengan informasi dan komunikasi merupakan salah satu faktor penyebab pergeseran paradigma yang ada selama ini. Hal ini membutuhkan strategi pemasaran yang baik agar Perguruan tinggi swasta mampu bertahan di tengah persaingan yang ketat antar Perguruan Tinggi satu dengan yang lain. Dalam menarik minat siswa yang baru lulus dari SMA agar masuk Perguruan tinggi, dibutuhkan adanya promosi yang menarik dan efektif, harga yang kompetitif dibanding dengan harga yang ditawarkan Perguruan tinggi lainnya. Kualiatas serta fasilitas yang bermutu akan mampu memberikan kepuasan terhadap masyarakat yang ingin kuliah.

Keputusan bagi calon mahasiswa untuk melanjutkan studi pada tempat studi yang diinginkan adalah suatu keputusan di mana calon mahasiswa melakukan pertimbangan-pertimbangan yang disesuaikan dengan keadaan atau kondisi yang ada. Jika keadaan atau kondisi yang terlihat tidak sesuai dengan apa yang diharapkannya, maka akan terjadi keraguan yang dapat berakibat pada keputusan untuk tidak memilih, dalam hal ini keputusan untuk tidak melanjutkan studi di tempat yang diharapkan. Pada kenyataannya pembuatan pilihan memiliki banyak dimensi dan dampak. Memilih merupakan bagian dari suatu upaya pemecahan sekaligus sebagai bagian dari proses pengambilan keputusan.

Kualitas pelayanan (service quality) berkontribusi signifikan bagi penciptaan, diferensiasi, positioning, dan strategi bersaing setiap organisasi pemasaran, baik perusahaan manufaktur maupun penyedia jasa. Perspektif pengukuran kualitas bisa dikelompokkan menjadi internal dan eksternal. Kualitas berdasarkan perspektif internal diartikan sebagai zero defect atau kesesuaian dengan persyaratan, sedangkan perspektif eksternal memahami kualitas berdasarkan persepsi pelanggan, kepuasan pelanggan, sikap pelanggan, dan customer delight.

Promosi merupakan salah satu faktor penentu keberhasilan program pemasaran. Betapapun berkualitasnya sebuah produk, bila konsumen belum pernah mendengarnya atau tidak yakin bahwa produk itu akan berguna bagi mereka, maka mereka tidak tertarik membelinya. Pada hakikatnya, promosi merupakan elemen bauran yang berfokus pada upaya menginformasikan, membujuk, dan mengingatkan kembali konsumen akan merek dan produk perusahaan.

Berdasarkan tingkat keterlibatan pembelian, proses keputusan pembelian oleh konsumen dapat dibagi tiga macam: nominal (habitual) decision making, limited decision making, dan extended decision making. Proses extended making merupakan jenis keputusan yang paling lengkap, bermula dari identifikasi masalah atau kebutuhan konsumen yang dapat dipecahkan melalui pembelian produk tertentu. Untuk keperluan ini, konsumen mencari informasi tentang produk atau merek tertentu dengan mengevaluasi seberapa baik masing-masing alternatif tersebut dapat memecahkan masalahnya. Evaluasi produk atau merek akan mengarah kepada keputusan pembelian.

Rumusan Masalah Penelitian ini adalah: 1)Apakah kualitas pelayanan berpengaruh dan signifikan terhadap keputusan mahasiswa kuliah di STIE Bentara Persada Batam, 2) Apakah promosi berpengaruh dan signifikan terhadap keputusan mahasiswa kuliah di STIE Bentara Persada Batam, 3) Apakah kualitas pelayanan dan promosi secara simultan dan parsial signifikan terhadap keputusan mahasiswa kuliah di STIE Bentara Persada Batam.

Slywotzy menyatakan bahwa menciptakan dan memberikan nilai pelanggan superior kepada high value consumers bisa meningkatkan sebuah organisasi. E-ISSN: 2657-0300 Lembaga Penelitian dan Penerbitan Hasil Penelitian Ensiklopedia $\quad 95$ P-ISSN: 2657-0319 
Pengkuran kualitas pelayanan sulit dilakukan pada sektor jasa karena karateristik yang unik dari jasa itu: intagibility, heterogenity, inserapibility, dan perihability. Valarie A. Zeithaml, Leonard L. Berry mengemukakan Kualitas pelayanan merupakan merupakan perbandingan antara pelayanan yang diharapkan dengan pelayanan yang dirasakan apabila pelayanan yang diharapkan, kualitas pelayanan dipersepsikan baik dan memuaskan. Menurut Martin L. Bell dalam basu swasta dan Irawan promosi adalah semua jenis kegiatan pemasaran yang ditujukan untuk mendorong permintaan. Sedangkan menurut William G.Nikels dalam bukunya Basu Swasta dan Irawan promosi adalah arus informasi atau persuasi satu arah yang dibuat untuk mengarahkan seseorang atau organisasi kepada tindakan yang menciptakan pertukaran dalam pemasaran. Menurut Amirullah, keputusan pembelian adalah proses dimana konsumen melakukan penilaian terhadap berbagai alternatif pilihan dan memilih salah satu atau lebih alternatif pilihan dan memilih salah satu atau lebih alternatif yang diperlukan berdasarkan pertimbangan-pertimbangan tertentu.

Kotler dan Amstrong menjelaskan bahwa keputusan pembelian adalah membeli merek yang paling disukai. Menurut Kotler dan Armstrong, terdapat lima proses pengambilan keputusan yaitu: pengenalan kebutuhan, pencarian informasi, evaluasi alternatif, keputusan pembelian, dan perilaku pasca pembelian. Keputusan pembelian adalah hasil akhir dari pertimbangan-pertimbangan merek, harga, kualitas yang dilakukan konsumen dalam memilih barang atau jasa pada pembelian.

\section{B. Metodologi Penelitian}

Jenis penelitian ini adalah penelitian deskriptif kuantitatif. Penelitian ini disebut penelitian deskriptif karena penelitian yang dilakukan dengan tujuan utama untuk memberikan gambaran atau deskripsi tentang suatu keadaan secara objektif. Sukmadinata (2015) penelitian deskriptif adalah suatu metode yang ditujukan untuk menggambarkan fenomena-fenomena yang ada, yang berlangsung pada saat ini atau saat yang lampau.Penelitian kuantitatif merupakan data penelitian yang berbentuk angka atau data kuantitaif yang diinginkan atau scoring (Sugiyono, 2016).Penelitian deskriptif kuantitaif merupakan pengumpulan dan pengukuran data yang berbentuk deskripsi dan angka. Dalam frekuensi variabel penelitian menggunakan 3 variabel yang terdiri dari 2 variabel bebas dan 1 variabel terikat. Variabel bebas terdiri dari kualitas pelayanan $\left(\mathrm{X}_{1}\right)$ dan Promosi $\left(\mathrm{X}_{2}\right)$ dan variabel terikat yaitu keputusan mahasiswa (Y), Responden yang digunakan adalah mahasiswa STIE Bentara Persada Batam, sebanyak 70 responden, dan dalam penelitian ini, data diolah menggunakan SPSS versi 22.

\section{Hasil dan Pembahasan}

Berdasarkan hasil pengujian secara statistik dapat dillihat dengan jelas bahwa secara parsial (individu) semua variabel bebas berpengaruh terhadap variabel terikat, dari hasil determinasi diperoleh nilai $\mathrm{R}$ sebesar 0,418 atau 41,8\% variabel kualitas pelayanan memiliki pengaruh terhadap keputusan mahsiswa sebagai variabel independen. Sedangkan dari nilai $\mathrm{R}^{2}$ sebesar 0,175 atau $17,5 \%$ variabel kualitas pelayanan mampu di jelaskan oleh keputusan mahasiswa sebagai variabel independen dan sisanya $82,5 \%$ keputusan mahasiswa oleh faktor lain yang tidak di teliti dalam penelitian ini. 
Penjelasan dari masing-masing pengaruh variabel adalah sebagai berikut: Pengaruh kualitas pelayanan terhadap keputusan mahasiswa hasil pengujian hipotesis $\left(\mathrm{H}_{1}\right)$. Pengujian ini membuktikan terdapat pengaruh yang signifikan antara kualitas pelayanan terhadap keputusan mahasiswa. Melalui perhitungan yang telah dilakukan diperoleh nilai $t_{\text {hitung }}$ sebesar 2,024 $>t_{\text {tabel }}$ sebesar 1,996 dengan signifikan sebesar $0,047<0,05$, dengan demikian $\mathrm{H}_{1}$ diterima dan $\mathrm{H}_{0}$ ditolak. Pengujian ini secara statistik membuktikan bahwa kualitas pelayanan berpengaruh positif dan signifikan terhadap keputusan mahasiswa kuliah di STIE Bentara Persada Batam.

Hasil penelitian ini sejalan dengan hasil penelitian terdahulu yang telah dibuktikan oleh Trias Setyowati dengan judul “ Analisis Service Quality, Promotion, Cost Study dan Dampaknya pada Minat Kuliah di Perguruan Tinggi" di dasari dengan subjek penelitian pada Universitas Muhammadiyah Jember di Fakultas Ekonomi. Dari analisis data yang dilakukan menunjukkan bahwa terdapat pengaruh yang signifikan dari keempat variabel yaitu kualitas pelayanan sebesar 0.243 , promosi sebesar 0.172 , biaya pendidikan sebesar 0.706 dan pencitraan sebesar 0.251 terhadap minat kuliah di Universitas Muhammadiyah Jember.

Pengaruh promosi terhadap keputusan mahasiswa hasil pengujian hipotesis $\left(\mathrm{H}_{2}\right)$. Pengujian membuktikan tidak terdapat pengaruh yang sigmifikan antara promosi terhadap keputusan mahasiswa. Melalui perhitungan yang telah dilakukan diperoleh nilai $t_{\text {hitung }}$ sebesar $0,813<t_{\text {tabel }}$ sebesar 1,996 dengan taraf signifikan sebesar 0,419> dari 0,05 dengan demikian $\mathrm{H}_{2}$ ditolak dan $\mathrm{H}_{0}$ diterima. Pengujian ini secara statistik membuktikan bahwa promosi tidak berpengaruh negatif dan signifikan terhadap keputusan mahasiswa.

Hasil penelitian ini sejalan dengan hasil penelitian terdahulu yang telah dibuktikan oleh Teguh Budiyanto dengan judul " Strategi Promosi, Kualitas Produk, dan Desain terhadap Keputusan Pembelian dan Minat Mereferensikan Rumah pada Puri Camar Liwas PT. Camar Sapta Ganda" dengan subjek penelitian pada PT Camar Sapta Ganda. Pengaruh kualitas dan promosi secaras simultan terhadap keputusan mahasiswa hasil pengujian hipotesis $\left(\mathrm{H}_{3}\right)$

Pengujian membuktikan bahwa secara simultan (bersama-sama) antara kualitas pelayanan dan promosi terdapat pengaruh signifikan terhadap keputusan mahasiswa. Dari hasil olahan data SPSS versi 22 menunjukkan nilai $F_{\text {hitung }}>F_{\text {tabel }} 7,098>3,134$ dengan tarif signifikan sebesar 0,002 nilai Sig ini lebih kecil dari 0,05 maka $\mathrm{H}_{0}$ ditolak $\mathrm{H}_{\mathrm{a}}$ diterima artinya bahwa kualitas pelayanan dan promosi secara bersama-sama mempunyai pengaruh signifikan terhadap keputusan mahasiswa.

\section{Penutup}

Berdasarkan hasil penelitian dan pembahasan maka dapat disampaikan beberapa kesimpulan penelitian sebagai berikut: Pertama, Hasil dari tabel menunjukkan bahwa kualitas pelayanan memiliki $t_{\text {hitung }}$ sebesar 2,024 sedangkan $t_{\text {tabel }}$ sebesar 1,996 dikarenakan $t_{\text {hitung }}>t_{\text {tabel }} 2,024>1,996$ dan tingkat signifikansi $=0,047<0,05$ maka $\mathrm{H}_{0}$ ditolak. Artinya berpengaruh positif dan signifikan terhadap keputusan mahasiswa kuliah di STIE Bentara Persada Batam. Kedua, Hasil dari tabel menunjukkan bahwa promosi memiliki $t_{\text {hitung }}$ sebesar 0,813 sedangkan $t_{\text {tabel }}$ sebesar 1,996 dikarenakan $t_{\text {hitung }}$ $<\mathrm{t}_{\text {tabel }}(0,813<1,996)$ dan tingkat signifikansi $=0,419>0,05$ maka $\mathrm{H}_{0}$ diterima. Artinya promosi tidak berpengaruh negatif dan signifikan terhadap keputusan mahasiswa kuliah di STIE Bentara Persada Batam. Ketiga, Berdasarkan tabel maka diperoleh hasil nilai $\mathrm{F}_{\text {hitung }}$ sebesar 7,098 sedangkan $\mathrm{F}_{\text {tabel }}$ sebesar 3,134 dikarenakan $\mathrm{F}_{\text {hitung }}>\mathrm{F}_{\text {tabel }}$ 7,098 $>$ 3,134 dan diperkuat dengan nilai signifikan sebesar 0,002 lebih 
kecil dari nilai kritik sebesar 0,05 maka $\mathrm{H}_{0}$ ditolak dan $\mathrm{H}_{\mathrm{a}}$ diterima yang artinya kualitas pelayanan dan promosi secara simultan atau secara bersama-sama berpengaruh signifikan terhadap keputusan mahasiswa kuliah di STIE Bentara Persada Batam

\section{Daftar Pustaka}

Abdullah, Ma'aruf. Metodologi Penelitian Kuantitatif. Yogyakarta: Aswaja Pressindo, 2015.

Aprilia, Kuncoro, H, Arifin, Zainil, Hidayat, Kadarisman. Pengaruh Karateristik Konsumen Terhadap Keputusan Pembelian, Jurnal Administrasi Bisnis, Vol. 37, No. 2, Agustus2016.

Clinton, Febriano, P, Mananeke Lisbeth, Taroreh, N, Rita. Analisis Pengaruh Harga, Promosi, Lokasi, dan Kualitas Pelayanan Terhadap Keputusan Pembelian pada PT. Indomaret Manado Unit Jalan Sea, Jurnal EMBA, Vol, 6 No. 4, September 2018.

Duli, Nikolaus. Metode Penelitian. Batam: STIE Bentara Persada, 2017.

Herlambang, Susatyo. Basic Marketing Yogyakarta: Gosyen Publishing, 2014.

Kotler, Philip. Manajemen Pemasaran Edisi Kesepuluh jilid II. Jakarta: PT.Ikrar Mandiriabadi, 2002.

Kotler, Philip. Manajemen Pemasaran. Jakarta: Prenhallindo, 2002.

Maharani, Dewi, P, Laily, Dewi P, Pengaruh Kualitas dan Kepuasan Pelanggan Terhadap Pembelian Ulang, Jurnal Inspirasi Bisnis dan Manajemen, Vol. 2 No. 1, Tahun 2018.

Moch Abdi, S. E., \& Hariyadi, M. M. (2017). Pengaruh Bauran Promosi Terhadap Keputusan Mahasiswa Memilih Universitas Muhammadiyah Sumatera Barat. Menara Ilmu, 11(77).

Priyatno Dewi. Mandiri Belajar SPSS-Bagi Mahasiswa dan Umum. Yogyakarta: Mediakom, 2008.

Rachmayanti, Irine, Utammi, Sri A. Kualitas Produk Sebagai Variabel Pemicu Utama Keputusan Pembelian Susu Formula SGM Eksplore Di Kota Surabaya, Jurnal Bisnis dan Manajemen, Volume 2, Nomor 1, Februari 2018.

Setyowati, Trias. Analisis Service Quality, Promotion, Cost Studydan Image

Dampaknya Pada Minat Kuliah di Perguruan Tinggi. Jurnal Manajemen dan Bisnis Indonesia, Vol.1, No.2, Desember 2015.

Sugiyono. Metode Penelitian Kuantitatif, Kualitatif dan R\&D. Bandung: Alfabeta, 2009.

Suliyanto. Ekonometrika Terapan Teori \& Aplikasi Dengan SPSS. Yogyakarta: Andi Offset, 2011.

Tjiptono, Fandy, \& Gregorius Chandra. Service, Quality, Satisfaction Edisi 4. Yogyakarta: Andi Offset, 2016.

Tjiptono, Fandy. Strategi Pemasaran Edisi 4. Yogyakarta: Andi Offset, 2015.

Wiratna Sujarweni, V. Metodologi Penelitian Bisnis \& Ekonomi. Yogyakarta: Pustaka Baru Press, 2015. 